\title{
PENSAMIENTO \\ DE JOSÉ VASCONCELOS
}

Santiago Vidal M.

Transcurren los siglos y el espíritu filosófico europeo continúa con su vigencia inspiradora y fecundante, al ser cada vez repensado y revalorado en nuevas circunstancias y perspectivas socio-históricas y culturales. Cristóbal Colón descubrió rutas geográficas para expandir la civilización occidental y también nuevas rutas al espíritu en el nuevo capítulo de la Humanidad que significó el Descubrimiento.

Realizamos con frecuencia conmemoraciones muy significativas y estimulantes de algunos de los grandes genios europeos. Es de toda justicia que también nos demos tiempo alguna vez para rememorar el legado de los pensadores latinoamericanos, de algunas de sus grandes figuras que han contribuido a la ciencia y la filosofía universal desde tierras americanas. Es en este ámbito y en el campo de la Historia de las Ideas en América. Es donde instalamos hoy la conmemoración a Vasconcelos, el maestro Vasconcelos como se le conoce en México, junto a Antonio Caso y otros. Tuvo una personalidad multifacética, fue Rector de la Universidad Nacional de México, Ministro de Educación reformador de la educación mexicana, fundador de la Sociedad Mexicana de Filosofía. Participó activamente en la Revolución de 1910 a 1915 que generó transformaciones políticas y sociales en su patria.

Vasconcelos estuvo en dos ocasiones en Chile. La primera de 1922, cuando aparecía Desolación de Gabriela Mistral, a quien estimó y ayudó en su condición de Ministro cuando Gabriela estuvo en México, época de auge del positivismo. En la segunda ocasión, unas tres décadas después, fue recibido por la Universidad de Chile y participó en inolvidables coloquios con catedráticos chilenos.

A continuación, haré una sucinta presentación de algunas ideas filosóficas de Vasconcelos que estimo primordiales para una mejor comprensión de su obra total, filosófica y cultural. El limitado tiempo disponible hace imposible excursionar por otros múltiples y variados campos de su obra y de su interesante vida en el contexto del pensamiento $y$ de la vida latinoamericana del siglo $x \mathrm{x}$. 
El pensamiento de José Vasconcelos ha de ubicarse en la línea del antipositivismo de fines del Siglo XIX, conjuntamente con el grupo de los llamados "fundadores" d la filosofía latinoamericana, entre otros, don Enrique Molina, de Chile. Su posturo se caracteriza, en general, como reacción anti-intelectualista, con acentos irracionales y vitalistas.

Una de sus predilectas fuentes en la Antigüedad griega, fue la del pensamientc pitagórico, el cual le dio la simiente a su teoría rítmica. De los clásicos leídos, recibió, además, inspiración de Heráclito, Platón y Plotino, y de Leibnitz en los tiempos modernos. Asimismo, fue de importancia la contribución que tuvo de algunos grandes románticos, tanto en el campo conceptual, útil para su revaloración, de la intuición emocional. Entre los filósofos del siglo xix influyentes en Vasconcelos, figura el idealismo alemán en la línea de Schelling. Además hay que agregar a Schopenhauer, Nietzsche y, sobre todo, el vitalismo e intuicionismo de Henry Bergson. Del Oriente le interesó el Veda primitivo del pensamiento indostánico.

Bien sabía el filósofo que había pasado la época histórica de los grandes sistemas filosóficos, pero se propuso investigar y crear una cosmovisión desde tierras americanas, la cual ha sido considerada una de las más originales contribuciones de hispano-parlantes a la Filosofía Latinoamericana. Como se dice, para Vasconcelos "la filosofía es una visión del universo que comienza con la onda magnética y termina con la Trinidad, definida por San Pablo".

Como una línea directriz de su pensamiento, diremos que Vasconcelos tiene otras modalidades de explicitar su pensar: filosóficamente, poéticamente, racionalmente y religiosamente.

En general, se empeña en pesquisar en las bases de un sistema metafísico universal, fundado en ciertas categorías metafísico-estéticas por sobre las exclusivamente matemáticas y mecánicas.

Para los efectos de nuestro propósito señalaremos sucintamente algunas obras de especial relieve filosófico en su itinerario espiritual. La obra que significaría el punto de partida de su monismo estético, es la obra Pitágoras: Una Teoría del Ritmo, de 1916. Constituye una interpretación estética del pitagorismo a partir de la teoría de los números, que eran esenciales de todas las cosas. El "Monismo Estético", se publicó dos años después (1918). Allí destaca el hecho de que su sistema no se funda en la razón pura ni en la razón práctica kantiana, sino "en el misterio del juicio estético". Expresa que el principio unificador de la actividad intelectual, moral y estética, la buscó en la crítica kantiana del juicio estético.

La obra "Revulsión de la Energía; los ciclos de la fuerza, el cambio y la existencia", es una suerte de sintesis del Monismo Estético. Por fin, el pensamiento de Vasconcelos se formula en una trilogía de obras fundamentales que le dan sentido 
al sistema. Ellas son, "El Tratado de Metafísica", de 1929, en el cual estudia al Ser en sus manifestaciones formales; la "Ética" que lo considera como acción, publicada en 1932 y la "Estética" en 1935, todo un tratado; en este libro considera al Ser "en cuanto realizado y cumplido en un propósito eterno - como dice- o bien entregándose a ritmos de movimientos de ascensión y sobrenaturales".

Con posterioridad a esas obras, en 1945 apareció su "Lógica Orgánica". En ella se ve que el pensamiento opera orgánicamente, refiriendo cada cosa a un conjunto y éstos a grados superiores por el valor vital y espiritual, no como ocurre en la lógica corriente, según comprensión y extensión de los conceptos. Las reflexiones medulares de su filosofía Vasconcelos las vierte sintéticamente en un libro titulado "Todología" (1952). Son incontables otras publicaciones de Vasconcelos, y son incontables los estudios publicados sobre su vida y su obra.

Desde temprano Vasconcelos se orientó hacia un panteísmo estético, en esta primera etapa de su filosofía. Su sistema, en lo fundamental, lo completa con la obra "La Revulsión de la Energía y los Ciclos de la Fuerza, el Cambio y la Existencia", de 1924; el "Tratado de Metafísica" publicado en 1929 y su "Ética", en 1932. En la búsqueda del punto de partida pueden señalarse los siguientes pasos complejos del pensamiento de Vasconcelos. El dato primero, que nos hace recordar a Descartes y del cual no se duda para la construcción de un universo poético, es la realidad misma, el NOUMENO, LA EXISTENCIA.

La existencia es el denominador común, de la realidad inmaterial existente en donde toma corporeidad la FORMA y la existencia de las cosas (Met., 41).

Se trata en verdad del SER y de la EXISTENCIA universal, antes de la separación del Yo y del NO-Yo. Antes está la fusión total, la existencia general. Con las cautelas del caso, este planteamiento hace recordar el idealismo de Richte.

La existencia, como DATO primero, conduce a Vasconcelos a concebir una ESENCIA MULTIEXPRESIVA, que llamamos materia; ésta a) es captada por los órganos sensoriales y es calculable por las matemáticas; b) pero, esa esencia se vuelve ESPÍRITU en la CONCIENCIA humana, "o al menos en el corazón", como dice (Met. 5).

De esta manera, a) primero tenemos "la fusión primordial realizada por esa esencia"; b) después, viene la separación entre el yo y el mundo (no-yo). Tal separación provoca incontables problemas, sobre todo de orden epistemológico.

Hay dos ideas significativas. En lo esencial, este filósofo revitaliza la concepción emanentista de Plotino, aun cuando se habla de que sus ideas tienen un trasfondo religioso cristiano, y aun cuando, con posterioridad, Vasconcelos aceptó la idea de la Creación del cristianismo. Este autor introduce dos ideas que de una u otra manera estarán presentes:

a) La primera, LA NOCIÓN DE ENERGía que sustituye a la idea de "sustancia" en la vieja concepción emanentista plotineana.

b) La segunda, es la idea de Evolución en el universo, concebida en un sentido 
emergentista y orientada hacia la transformación de la energía cósmica en BELLEZA que es el estamento superior y "más perfecto de la energía primitiva". EI pensamiento de Vasconcelos no es una doctrina evolucionista.

Se habla de monismo estético, pues la energía es considerada uiva esencia que se organiza cíclicamente y procede por tríadas; el paso de un ciclo a otro constituye un cambio de ritmo, de plan y de orientación.

Un problema central, es el relativo a la sustancia y la esencia del hombre y del mundo. No obstante la separación necesaria, "la esencia del hombre y la esencia del mundo son una y una misma cosa". Vasconcelos dice que "hay que entender SUBJETIVIDAD POR CONCIENCIA DEL SER MISMO, el ser del hombre en todo caso es dinámico.

La sustancia primera y primordial que unifica, es una ACCión, una energía. No es algo meramente sustancial estático. Esta sustancia es UNA, aun cuando no se sepa cómo lo es. Se encuentra en estados de "catástrofe", es decir de total dislocación, desarrollándose en dos cauces: a) hacia la desintegración y la nada originaria. (Considerar en esto la física de Carnot, la termodinámica y la teoría electrónica). b) El otro cauce, lo constituye un proceso de ascenso desde la calidad fenomenal material, hasta los complejos procesos del espíritu. Ascenso que revela la física "desde que el fenómeno adopta los ritmos de la física cuántica)"...

Aun cuando se haya criticado ciertas interpretaciones de la física contemporánea Vasconcelos cree que el saber contemporáneo está más próximo a la verdad originaria pues la ciencia tiende a ver la naturaleza, "movida por una energía misteriosa, en cuanto no se sabe qué es en definitiva y cuál es su origen".

Un comentarista mexicano sustenta la hipótesis aclaratoria de que ese proceso no se produce por masas y mecánicamente, sino "POR INDIVIDUACIONES ESTRUCTURALMENTE", es decir, "una estructura es el punto inicial de un proceso de reversión que tiene por meta final el retorno al SER ABSOLUTO, que es DIOS". En varias explicitaciones del pensamiento de José Vasconcelos, hay ciertas aproximaciones con el pensamiento de Teilhard de Chardin las que sería necesario estudiar cuidadosamente, más aún si tenemos en cuenta las fecha de las publicaciones de las obras de ambos coetáneos como representaciones fáciles, pensemos en las mencionadas ideas de disgregación de la energía y su regreso a la nada, y la de reintegración de la energía en el CREADOR, hacen pensar en la "estofa" primordial de Teilhard de Chardin con la imagen bíblica del itinerario desde el ALFA hasta la cúspide del Espíritu, que es OMEGA.

Respecto a la teoria del ritmo, Vasconcelos busca solución al problema propio de todo Monismo, el cual apunta a esta pregunta crucial: ¿cómo es posible que estando todos los OBJETOS del universo sustentados por una misma distancia, sean tan diversos e irreductibles entre si? Notables filósofos enfrentaron en el pasado este mismo problema, tales como Parménides, Plotino, Escoto, Orígenes, Spinoza, 
etc. Vasconcelos repensó a Pitágoras, quien concebía la sustancia como dinámica y no de otro modo. La respuesta surge reiterada: "la diversidad de los objetos constituidos por una misma sustancia, obedece al ritmo en que ella se da en éstos". Así, la Teoría de los Ritmos da respuesta a la pregunta de origen monista.

Es indudable que la inclinación de Vasconcelos hacia una forma de PANTÉ́SMO ESTÉTICO, plantea diversos problemas implicados. Únicamente es posible aqui subrayar algunos. (Mon. Estet. 16). Si hay dos momentos, el SUBJETIVO Y el OBJETIVO, aún siendo uno mismo como dos caras de una moneda, tal vez, son, sin embargo, en esencia CAPACES DE DOS RITMOS DE DIRECCIÓN INDEPENDIENTE. La ciencia ayuda a mostrar que esos ritmos y direcciones no son siempre los mismos. En esta concepción vasconceliana, haY TRES RITMOS INDEPENDIENTES, correspondientes a tres estructuras: fisica, biológica y espiritual.

Las Revulsiones. Las llamadas "revulsiones" son "saltos" de la energía de una estructura de la realidad a otra. El paso de un ciclo a otro nuevo ciclo, transforma el sentido y el valor del precedente. Esto significa, en verdad, repetición mecánica en el átomo, finalidad en la célula y libertad y creación en la conciencia humana. Estas revulsiones se manifiestan en todos los procesos y expresiones de la energía cósmica. El autor dice que damos estas denominaciones, porque no las comprendemos bien.

Patrick Rommanell ha comprobado que "la revulsión de la energía" significa una síntesis perfecta del monismo estético; representa en la obra el mismo papel que en Leibnitz representó La Monadología.

El Ritmo de lo físico, en general, es propio del ÁTomo. Éste constituye una organización de la materia (protones, electrones, otras partículas subatómicas) organización que no es "suma sino una estructura. Ciertamente, se puede aventurar la presencia de nociones propias del estructuralismo de la Gestalt. Un buen tema de investigación...

El ritmo de lo físico es un ritmo recurrente, puramente repetitivo, algo así como si la energía se detuviese sin poderse transformar. Se comprende como un PRINCIPIO DE CAUSALIDAD. Se entiende por acto de repetición, el que asume una potencia latente, sin orientarse a otro fin que la mera repetición de los mismos ritmos y modificaciones en varios grados, sin cambiar de dirección. Este comportamiento es propio de los seres físicos en el mundo natural. El movimiento es la INERCIA que surge desde esa originaria energía indiferenciada.

Esta primera revulsión coincide con la aparición de lo físico desde aquello que para nuestra mente es la NADA. Cada variación de este ritmo genera un objeto físico distinto. Se da como ejemplo las variaciones en las ondas luminosas que determinan colores variados del espectro, o las diferentes ondas vibratorias que determinan temperaturas variadas. En resumen, las alteraciones de los ritmos de la energía en este campo de lo físico, son esencialmente cuantitativas, y no cualitativas. Cantidad y tiempo pueden explicar aspectos de la fisis. 
El ritmo biológico se manifiesta en la célula, que es, a su vez, una estructura radicalmente diferente de sus parcelas, pero que no puede prescindir de ninguna de ellas sin dejar de ser "lo que es", sin perder su identidad. Es en este orbe de la realidad orgánica en donde se aprecia mejor el concepto utilizado por Vasconcelos de estructura dinámica. Un ejemplo típico es el de la molécula de aguA, $\mathrm{H}_{2} \mathrm{O}$. Hidrógeno y Oxígeno separados, no son agua. Sólo se constituye agua si están organizados sus ritmos para ello.

En estos análisis, Vasconcelos critica la fenomenología, pues al "concepto de lo esencial y de lo accidental de un OBJETo opone el concepto de la estructura de ese objeto. Dice el filósofo, que "se asesina lo particular, lo concreto; en la estructura se le aprovecha; lo concreto y particular no sobra, SINO OUE AYUDA A LA INTEGRACIÓN DEL OBJETO, es esencial al objeto".

En este tema, surge otro interesante enfoque para la teoría de la realidad y la teoría del conocimiento. Si la estructura NO ES Una ESENCIA PURA, puede ser una estructura de heterogéneos. La esencia lo es siempre de una clase de objetos homogéneos. Las partes son todas idénticas entre sí, sin diferencias cualitativas. En el ejemplo de la molécula de agua, la estructura es una síntesis de heterogéneos. Las partes del todo heterogéneo, presentan diferencias, sobre todo de estructura y función.

Frente a este planteamiento, en el fondo de crítica a la Fenomenología, Vasconcelos muestra que se trata de dos planos diferentes: a) Uno es el plano de lo IDEAL, de la conciencia trascendental, (la esencia, clase de los homogéneos). b) El otro plano es el de lo FÁctıCO, síntesis de los heterogéneos. Este último tiene su correspondencia en el plano del espíritu y no en el plano de lo ideal. Digamos algo respecto a esta cuestión relacionada con el problema del conocimiento. En esta faceta del pensamiento, Vasconcelos insiste en la ESTRUCTURA: el SER, SíNTESIS DE HETEROGÉNEOS, "redime la materia primordial de su dispersión y aniquilamiento".

Al respecto hay que recordar la crítica del pensamiento actual a la concepción mecanicista del universo, por no "haber podido reducir sus diferentes planos a un denominador común". Vasconcelos en esto introdujo el milagro, elemento irracional.

La unificación de los heterogéneos tiene importancia enorme en la resolución del problema de superar el dualismo-sujeto-objeto. Vasconcelos opone el conocimiento lógico al conocimiento estético. El primero no logra la superación del dualismo gnoseológico. En cambio, el conocimiento estético rompe el contraste al unificar los heterogéneos. Así se explica que defina la Estética como "arte de arreglar los heterogéneos"; éstos logran verdadera significación en el orbe puro de la existencia plácida, propia del alma humana.

La vida aparece en un nuevo salto o revulsión en el campo métrico de lo físico y químico. Marca una suerte de progreso y constituye elementos y estructuras que sirven de sustentación a la VIDA. Mientras el átomo repite acciones y reacciones y 
sólo depende de la cantidad de la carga y distribución de la energía, la célula, en cambio, es un centro productor de impuLsos. Éstos tienden a organizarse para cumplir determinados FINES nutritivos, defensivos, etc. (Metaf. 193).

El universo biológico se explica TELEOLÓGICAMENTE, aunque sea en forma rudimentaria, a diferencia del átomo, esclavizado por la inercia y la monotonía. La célula es un esfuerzo hacia la INDIVIDUACIÓN DE LO ORGÁNICO, y de su conservación depende la existencia de los seres vivos. Estas individuaciones poseen el ESPACIO en común. Cada ser, individualmente constituido, atrapa, capta, toma según sus capacidades de la fuente común de energía. Toma la sustancia indispensable, transformándola según sU FINALIDAD asociándola a su existenvia individual, no bien aclarada... Así, el ser orgánico posee su individualidad y ésta queda sujeto a finalidad.

La estructura biológica incorpora, por lo tanto, los estratos físico-químicos y le "agrega" la vIDA que es un organizar la energía conforme a una finalidad. Aun cuando no se ahonda ese "agregar vida" o incorporar vida a lo que no es vida, EL ORGANISMO EJERCITA CIERTA "DECISIÓN", según un fin que le conviene en ese medio. En estas ideas se ve a Vasconcelos "postular cierta libertad en el universo biológico", lo que sería una contribución moderna a la Filosofía de las Ciencias Biológicas. No se podría identificar tal "decidir" con la auténtica LIBERTAD ESPIRITUAL del hombre. Nos preguntamos, ¿este ser biológico, es la antesala del ser humano?

Ritmo de lo espiritual. En esta concepción, la estructura de lo biológico que significa VIDA, sirve de saber al ESPírITU. Como dice Vasconcelos, esta tercera estructura superior es el ALMA, de cuya "salvación depende el acrecentamiento y la victoria del espíritu". Esta suprema revulsión conocida, lleva la energía al campo ESPIRITUAL. Corresponde singularizar al hombre en términos de espíritu. En este punto de las ideas filosóficas de Vasconcelos, tenemos otra interesante teoria: LA FUNCIÓN DEL HOMBRE EN EL COSMOS SE REALIZA A TRAVÉS DEL CONOCIMIENTO. Tal peso tiene esta idea que lleva a su autor a afirmar que "el conocimiento se identifica con la totalidad de la vida humana. De esta manera, las diversas ciencias son formas de vida del hombre. Pero, el conocimiento no es sinónimo de pensamiento, pues el conocimiento es más amplio que el pensamiento. El conocimiento tiene la virtud de reducir a términos de CONCIENCIA los elementos más extraños, haciéndolos, participar de nuestra vida, según afinidad con cada persona". (Metaf. 136). El conocimiento en Vasconcelos NO ES ÚNICAMENTE LO RACIONAL, ni siquiera lo conciencial estricto". Esto se entiende, si examinamos su posición con la óptica irracionalista. El hombres es una ESTRUCTURA, sinónimo de vida humana en su totalidad. Me atrevo a pensar en una cierta noción de hombre íntegro, completo, respecto a esa totalidad de la vida humana. En sentido estrictamente funcional, el conocimiento se identifica con la vida humana misma. Concebido el hombre como la totalidad de su ser, pasa a ser el único medio por el cual "LA ENERGía PUEDE REDIMIRSE Y ALCANZAR UN NIVEL ESPIRITUAL SUPERIOR". 
Vasconcelos considera que si una parte de la existencia "se salva", se redime con ella al universo entero. "Cada vez que se salva una alma, se salva y se lleva con ella al universo transfigurado". Este concepto de redención en el ámbito de la humanidad es de orden religioso, más que filosófico, aunque parece inserto en el problematismo filosófico, por ejemplo, en el saber de salvación de Max Scheler. Además, esta concepción del hombre en Vasconcelos, también nos hace ver alguna relación digna de estudio en el hombre como un microcosmos, también de Scheler. Pero esto ha tomarse aquí como una simple hipótesis de trabajo. Si reunimos algunas ideas, diremos que hay interrelaciones entre los tres niveles, estructuras de la realidad y el juicio estético:

1. La unidad y pluralidad se plantea de esta manera: "La sustancia es una de las individuaciones genéricas que llamamos átomos, células, almas, son esfuerzos de recomposición hacia la Unidad" (Estética, p. 166).

2. La concentración de materia y energía, es signo de CREACIón, de palingenesia o renacimiento de los seres. A pesar de haber sido advertidas ciertas resonancias de la idea de emanación de Plotino en Vasconcelos se perfila claramente a través de la evolución de su pensamiento, el concepto de creación cristiana. Sólo la energía desorganizada se dispersa y pierde. Si los campos métricos se rompen, la energía se disipa y la materia retorna a la NADA.

3. La existencia de lo físico, y lo biológico, como lo dice Vasconcelos, es el "misericorde soplo divino". "En sí misma esa existencia supone una revulsión que es REDENCIÓn de la energía".

4. La vida significa la revulsión máxima y, en ella, la LIBERTAD juega el gran rol en la estructuración del espíritu.

5. Se ha criticado al pensador de no haber establecido una clara relación entre dos planos diferentes de estos tres estadios, físico, biológico y espiritual, que en definitiva CULMINAN EN LO ESTÉTICO Y RELIGIOSO.

6. En última instancia el juicio estético se subordina a la REVELACión. La tendencia fideista y mística de Vasconcelos en su primera etapa, se ha explicado a partir de esta posición y actitud.

\section{Alcances sobre la Ética de Vasconcelos}

En la vida espiritual de estas concepciones de Vasconcelos, la Ética aparece un tanto extraña al sistema. Interesante resulta comprobar que la Ética figura en la clasificación de las Ciencias de este filósofo, al considerarlas "formas de vida". Así, hay ciencias de conocimiento de la naturaleza y de las matemáticas; ciencias del conocimiento del hombre, entre las cuales destaca la Ética, en cuanto acomodación de la conducta humana y la naturaleza que rodea al hombre, y la Estética como otra ciencia.

La concepción finalista del universo biológico le conduce a una peculiar teoría 
ética. La vida humana no es sólo conocimiento o formas intelectuales: es acción que ha de organizarse mediante la conducta ética. Rechaza el imperativo categórico de Kant y toda moral utilitaria. Formula una crítica a la moral de la era industrial, a las diversas limitaciones de la civilización tecnológica. También critica la posición eudemonista que transforma el bienestar material en el fin de la vida humana. El filósofo tampoco acepta una ética libre y desinteresada. Piensa que la "Ética no puede prescindir de la subordinación a los fines estéticos, a los fines sobrehumanos".

La vida humana para Vasconcelos es primordialmente creadora. Los valores son formas a priori, vitales de la acción en un ámbito espiritual dinámico. Los seres humanos al actuar, vamos creando nuestra personalidad...

En esta sucinta referencia al pensamiento ético de Vasconcelos, es menester comprobar que LA ÉTICA SE TRANSFORMA EN ESTÉTICA. En las formas superiores del Espíritu, se convierte en impulso religioso y místico.

\section{Lo religioso. Cosmogénesis y Dios}

El concepto de Dios es introducido por Vasconcelos en un universo catastrófico. Dios crea ese universo, el cual no es emanado de él. La sustancia o energía, por sí sola tiende, como se ha dicho, a desintegrarse y dispersarse. Se intenta ilustrar esta idea con un міто: "este caudal de energía es como el cuerpo de un inmenso demonio que va descendiendo hacia la NADA; pero la misericordia divina genera ejes estructurales que en espiral reintegran la energía al CREADOR".

El primer problema que se plantea esta cosmología, es el problema de Dios. Vasconcelos en su reflexión expresa que "la tesis que recurre al Dios eterno desde antes de los tiempos y en estado de reposo y plenitud, difícilmente justifica la existencia del devenir". El devenir y la CREACIÓN significan temporalidad; pero DiOS es intemporal. No obstante, lo anterior, se puede afirmar que el devenir es "una consecuencia del ACTO DE LA CREACIÓN QUE ECHÓ A RODAR LoS MUNDOS". (Metaf. p. 74). La razón no resuelve este problema, aun cuando muchos estiman satisfactorios los atisbos de la Revelación Divina. Esta cosmogénesis comienza, por tanto, por la Creación algo esencial en el Cristianismo, la cual, no obstante, es inexplicable racionalmente $y$, además, es misteriosa.

Los críticos que ha tenido Vasconcelos no ven con claridad total que cada una de esas estructuras, física, biológica y espiritual, sean sólo modificación de la energía. Pero, en el pensamiento de Vasconcelos, esas estructuras surgidas espontáneamente de la sustancia primaria o energía latente son, en definitiva, CREADAS POR DIOS.

Conversión de Vasconcelos al Cristianismo. Aun cuando la trayectoria espiritual de Vasconcelos de su vida, partió con una adhesión a una forma de monismo 
panteísta estético, el Cristianismo fue su meta final, su posición espiritual última hasta su muerte, ocurrida el 30 de junio de 1959.

Si retomamos su tesis central de las revulsiones o cambios bruscos de la energía, diremos que son la excepción en la relación de causalidad; son manifestación del MILAGRO, de la intervención divina. El filósofo, al respecto, afirma que "la energía sólo PUEDE REDIMIRSE, SI DIOS LA CREA Y LA SOSTIENE, si Dios le indica el fín y el sentido, "sin la MANO DE DIOS el universo se dispersa y desaparece". Para aproximarnos a estas ideas inscritas en el cristianismo, durante esta última etapa de su pensamiento, pensemos en un DIOS PROVIDENCIA, algo radicalmente opuesto a todo naturalismo monista y materialista. Recordamos que entre otros estudios últimos, Vasconcelos escribió incluso unas meditaciones sobre "lo TRINO", sobre la Santísima Trinidad. Hay una conocida y sugerente frase de este filósofo que apareció en un estudio de 1938 titulado "Desastre: Se puede perder la patria, pero no se debe renunciar al Cielo", fin último del espíritu.

"Un autor contemporáneo dice al respecto que si se concibe un universo totalmente explícito, desde el punto de vista racional-matemático", nos quedaremos "con la máquina cartesiana que Dios ha puesto a funcionar, sin preocuparse más de ella". Ese no es un Dios Providente.

Por último, en estos resúmenes de algunas ideas filosóficas de Vasconcelos hay que subrayar la índole PERSONALISTA que subyace en su filosofía. El filósofo no adhiere a un impersonalismo monista que habría resultado procedente en las primeras etapas de su filosofar. En este aspecto, también su filosofía se concilia con la ortodoxia y la fe del Cristianismo Católico.

En la síntesis última de su filosofía, llamada "Todología", José Vasconcelos busca el elemento unificador de la Filosofía, la Poesía y la Religión, vale decir la ciencia, el arte y la Revelación, con el objeto de alcanzar el ideal de la "armonía del saber total" que, en el fondo, tal vez sea una modalidad original de acuerdo del saber natural como el saber divino. Ésta, acaso, en definitiva la vocación humana y filosófica íntima del notable pensador mexicano, digno exponente de la cultura y espiritualidad de México y exponente de la Filosofía Latinoamericana. 